\title{
$A P O B$ gene polymorphisms may affect the risk of minor or minimal bleeding complications in patients on warfarin maintaining therapeutic INR
}

\author{
Jeong Yee ${ }^{1}$ Woorim $\mathrm{Kim}^{2} \cdot$ Byung Chul Chang ${ }^{3,4} \cdot$ Jee Eun Chung ${ }^{5} \cdot$ Kyung Eun Lee $^{2} \cdot$ Hye Sun Gwak $\mathbb{B}^{1}$
}

Received: 29 October 2018 / Revised: 17 May 2019 / Accepted: 28 May 2019 / Published online: 11 June 2019

(c) The Author(s), under exclusive licence to European Society of Human Genetics 2019

\begin{abstract}
The purpose of this study was to investigate influence of gene polymorphisms of $A P O B$ and $A P O E$ on risk of bleeding complications at therapeutic INR, during warfarin treatment in Korean patients with mechanical cardiac valves. The study included 142 patients from the EwhA-Severance Treatment Group (EAST) of Warfarin. A total of 12 SNPs was investigated. Five SNPs of $A P O B$ (c.13013G $>$ A, c.1853C $>$ T, c.1594C $>$ T, c.293C $>$ T, and c.7545C $>$ T) and five SNPs of APOE (g.4798T >G, g.6406G >A, g.10413T >C, c.388T >C, and c.526C $>$ T) were selected. In addition to selected SNPs, VKORC1 g.6399C $>\mathrm{T}$, and CYP2C9 c.1075A $>\mathrm{C}$, which were known to have significant effects on warfarin stable doses, were also included in the study. Two SNPs of $A P O B \quad($ c. $293 \mathrm{C}>\mathrm{T}$ and c.1853C $>\mathrm{T})$ were associated with bleeding complications. $\mathrm{T}$ allele carriers of c.293C $>\mathrm{T}$ had 8.6 times $(95 \% \mathrm{CI} 2.9-25.5, p<0.001)$ increased risk of bleeding, and attributable risk was $88.3 \%$. C allele carriers of c.1853C $>\mathrm{T}$ had 6.4 times $(95 \% \mathrm{CI} 2.3-17.9, p<0.001)$ increased risk of bleeding after adjusting for covariates (attributable risk of 84.3\%). AUROC values of models that included c.1853C $>\mathrm{T}$ and c. $293 \mathrm{C}>\mathrm{T}$ were 0.771 and 0.802 , respectively. Among demographic characteristics, age was the only significant factor. This study revealed that $A P O B$ was associated with bleeding complications in patients with warfarin treatment after mechanical cardiac valves.
\end{abstract}

The authors equally contributed: Jeong Yee, Woorim Kim

Kyung Eun Lee

kaylee@cbnu.ac.kr

$\triangle$ Hye Sun Gwak

hsgwak@ewha.ac.kr

1 College of Pharmacy \& Division of Life and Pharmaceutical Sciences, Ewha Womans University, 52 Ewhayeodae-gil, Seodaemun-gu, Seoul 03760, Korea

2 College of Pharmacy, Chungbuk National University, 660-1, Yeonje-ri, Osong-eup, Heungdeok-gu, Cheongju-si 28160, Korea

3 Department of Thoracic and Cardiovascular Surgery, Bundang CHA Medical Center, CHA University, 59, Yatap-ro, Bundanggu, Seongnam, Gyeonggi-do, Korea

4 Department of Thoracic \& Cardiovascular Surgery, Yonsei University Medical Center, 50-1 Yonsei-ro, Seodaemun-gu, Seoul 03722, Korea

5 College of Pharmacy, Hanyang University, 55 Hanyangdeahak-ro, Sangnok-gu, Ansan 15588, Korea

\section{Introduction}

Warfarin has been widely used as an oral anticoagulant to reduce risk of serious consequences, including heart attack and stroke. Although introduction of direct oral anticoagulant decreased use of warfarin, warfarin remains first-line antithrombotic therapy in patients with mechanical heart valves [1]. Substantial risk of thromboembolic events immediately following mechanical valve replacement, necessitates initiation of anticoagulant therapy with warfarin [2-4].

Despite these advantages, warfarin has a narrow therapeutic range and high interpatient variability, requiring frequent monitoring. International normalized ratio (INR) is used to monitor warfarin treatment, and recommended target INR for mechanical heart valve is 2.5 (range, 2.0-3.0) [5]. So far, most pharmacogenomics studies and guidelines for warfarin have been focused on initial therapeutic dose determination; [6] however, after stable doses are achieved, genetic information contributes little to warfarin dose prediction [7]. Although INR is routinely monitored during warfarin therapy for assessment of anticoagulation intensity and dose adjustment, some studies showed that patients 
could still experience bleeding complications within therapeutic INR, even at low INR $[8,9]$. This implies that the intensity of anticoagulation does not fully explain the reason behind bleeding events in patients.

Bleeding is the most serious complication of anticoagulation treatment. Although several bleeding risk scores such as HAS-BLED have been developed, they only include demographic and clinical factors, except for the HEMOR2RHAGES score, which includes CYP2C9 variants [10]. Some studies have been performed to evaluate the relationship between genotypes and bleeding [11]; however, as most studies deal with patients in the dosetitration phase, information on long-term warfarin therapy after INR stabilization is extremely scarce.

It has been studied that apolipoproteins are involved in platelet functions. Especially, apolipoproteins B (APOB) exist on the surface of low-density lipoprotein (LDL) particles [12]. LDL sensitizes platelets via binding of apoB-100 to a receptor on the platelet membrane and via transferring lipids to the platelet membrane. Moreover, apolipoprotein E $(A P O E)$ mediates inhibition of platelet functions by APOEcontaining lipoproteins such as high-density lipoproteins. So, it is reasonable to assume that gene polymorphisms of $A P O B$ and $A P O E$ may influence risk of bleeding during warfarin treatment. However, effects of these gene polymorphisms on bleeding complications in patients with warfarin treatment, have not been studied [13]. Therefore, the purpose of this study was to investigate influence of gene polymorphisms of $A P O B$ and $A P O E$ on risk of bleeding complications at therapeutic INR, during warfarin treatment in Korean patients with mechanical cardiac valves.

\section{Subjects and methods}

\section{Study patients and data collection}

Study patients were enrolled from the EwhA-Severance Treatment (EAST) Group of Warfarin. The study cohort consisted of 229 patients who had warfarin therapy, after mechanical heart valve replacement between January 1982 and December 2009 at Severance Cardiovascular Hospital of Yonsei University College of Medicine. Patients that maintained a stable INR (INR of 2-3 for at least three consecutive times) were eligible for the study. Patients that had experienced bleeding complications in supra or subtherapeutic INRs were excluded. Patients were also excluded if their complications were not verified by health professionals.

Patients were followed-up continuously at the outpatient clinic of Severance Cardiovascular Hospital of Yonsei University Medical Center. Blood samples were collected during regularly scheduled clinic visits. Data collection was performed from scanned medical records, and electronic medical records of patients June 1983-August 2010. Data including gender, age, body weight, height, position of valve prosthesis, valve type, warfarin therapy duration, INR measurements, concurrent medication, comorbidity, and history of bleeding complications were collected. Bleeding complications were classified as major life-threatening, other major, any major, minor, or minimal using the scheme detailed in Platelet Inhibition and Patient Outcomes trial [14]. Data of all 12 single nucleotide polymorphisms (SNPs) and related phenotype of bleeding were submitted to ClinVar (accession number: SCV000889936-SCV000889947). This study was approved by the Institutional Review Board of the Yonsei University Medical Center (approved number: 4-2009-0283). All patients gave written informed consent for participation.

\section{Genotyping methods}

Tag SNPs analysis was performed with minor allele frequency (MAF) of $\geq 10 \%$ in Japanese and Han Chinese populations using Haploview 4.2 [15]. Linkage disequilibrium (LD) blocks were constructed following the $\mathrm{D}^{\prime}$-method using the default algorithm in Haploview 4.2 and confirmed by the HaploReg 4.1 [16]. Based on LD pattern, tagSNP selection was performed with the pairwise tagging method $\left(r^{2} \geq 0.8\right)$. Based on previous research, NM_000384.2:c.7545C $>\mathrm{T}$ (p. $(T h r 2515=))$ in the $A P O B$ gene and NM_000041.3: c.388T $>C$ (p.(Cys130Arg)) and NM_000041.3:c.526C >T (p. (Arg176Cys))SNP in the APOE gene were also included $[17,18]$. A total of five SNPs of APOB (NM_000384.2: c.13013G $>$ A (p.(Ser4338Asn)), NM_000384.2:c.1853C $>$ T (p.(Ala618Val)), NM_000384.2: c.1594C >T (p.(Arg532Trp)), NM_000384.2:c.293C $>\mathrm{T}$ (p.(Thr98Ile)), and c.7545C $>\mathrm{T}$ ) and five SNPs of APOE (NG_007084.2:g.4798T $>$ G, NG_007084.2:g.6406G >A, NG_007084.2:g.10413T>C, c.388T $>\mathrm{C}$, and c.526 $\mathrm{C}>\mathrm{T}$ ) were selected. In addition to selected SNPs, NG_011564.1:g.6399C $>\mathrm{T}$ in the VKORC1 gene and NM_000771.3:c.1075A $>C$ (p.(Ile359Leu)) in the CYP2C9 gene, which were found to have significant effects on warfarin stable doses, were also included in the study. So, a total of 12 SNPs was investigated.

Genomic DNA from patients was isolated from ethylendiaminetetraacetic acid-blood samples using the QIAamp DNA Blood Mini Kit (QIAGEN GmbH, Hilden, Germany) according to protocol of the manufacturer. Genotyping was conducted using the TaqMan genotyping assay using real time PCR system (ABI 7300, ABI, Foster City, CA, USA).

\section{Statistical analysis}

Hardy-Weinberg equilibrium (HWE) was tested using a chi-square test. $\mathrm{LD}\left(\mathrm{r}^{2}\right.$ and $\left.\mathrm{D}^{\prime}\right)$ between two loci in the gene 
was calculated with Haploview 4.2 [15]. Continuous variables in patients with bleeding complications and those without complications were compared by Student's $t$ test. Chi-square test was used to compare categorical variables between the two groups, and Bonferroni correction was performed for 12 SNPs. Multivariate logistic regression analysis was used to examine independent risk factors for bleeding complications. Factors having $p<0.05$ or remaining significant after Bonferroni correction from univariate analysis, with clinically relevant confounders, were included in multivariate analysis. Odds ratio (OR) and adjusted odds ratio (AOR) were calculated from univariate and multivariate analyses, respectively. Attributable risk (\%) was calculated by $(1-1 / \mathrm{AOR}) \times 100$. Discrimination of the model was further assessed by analysis of the area under receiver operating curve (AUROC) that assesses the ability of the risk factor to predict bleeding. Hosmer-Lemeshow test was performed to confirm the model's goodness of fit. We calculated the number needed to genotype for preventing one patient from experiencing a significantly higher incidence of bleeding complications by 1/absolute risk reduction. Absolute risk reduction was obtained by multiplying the relative risk reduction by genotyping and risk of higher incidence of bleeding complications without genotyping. Post hoc power calculations were performed using Quanto 1.2.4 software (http://biosta ts.usc.edu/software). A $p$-value of less than 0.05 was considered statistically significant. All statistical analyses were performed with IBM SPSS statistics version 20 software (International Business Machines Corp., NY, USA).

\section{Results}

Of 229 patients from the EAST Group of Warfarin, 87 patients were excluded due to the following reasons; 28 patients did not reach stable INR, four patients had bleeding complications at supratherapeutic INR, and 55 patients reported minimal bleeding complications not verified by health professionals. Accordingly, data from 142 patients that underwent cardiac valve replacement were used for analysis. Median age of included patients was 60 years (range, 34-81 years). There were 52 (36.6\%) males. Follow-up periods ranged from 1.0 to 29.7 years. Mean INR monitoring interval was 2.9 months, and average number of INR measurements per patient was 23 .

As shown in Table 1, 21 patients (14.8\%) had bleeding complications at therapeutic INR. Among those 21 patients, 11 patients and 10 patients experienced minor bleeding and minimal bleeding complications, respectively. There was no significant difference between the two groups, except for atrial fibrillation. Patients with atrial fibrillation had more
Table 1 Patient characteristics of study patients

\begin{tabular}{|c|c|c|c|}
\hline \multirow[t]{2}{*}{ Characteristics } & \multicolumn{2}{|c|}{$\begin{array}{l}\text { Bleeding complication, } \\
\text { number }(\%)\end{array}$} & \multirow[t]{2}{*}{$p$} \\
\hline & $\begin{array}{l}\text { Presence } \\
(n=21)\end{array}$ & $\begin{array}{l}\text { Absence } \\
(n=121)\end{array}$ & \\
\hline Sex & & & 0.705 \\
\hline Male & $8(38.1)$ & $44(36.4)$ & \\
\hline Female & $13(61.9)$ & 77 (63.6) & \\
\hline Age (years) & & & 0.168 \\
\hline Mean \pm SD & $62.0 \pm 11.2$ & $58.7 \pm 10.0$ & \\
\hline Body weight $(\mathrm{kg})$ Mean $\pm \mathrm{SD}$ & $58.6 \pm 10.7$ & $58.7 \pm 10.4$ & 0.989 \\
\hline $\begin{array}{l}\text { Body mass index }\left(\mathrm{kg} / \mathrm{m}^{2}\right) \\
\text { Mean } \pm \mathrm{SD}\end{array}$ & $22.3 \pm 2.3$ & $22.5 \pm 2.8$ & 0.756 \\
\hline \multicolumn{4}{|l|}{ Comorbidity } \\
\hline Hypertension & $6(28.6)$ & $33(27.3)$ & 0.902 \\
\hline Diabetes mellitus & $3(14.3)$ & $10(8.3)$ & 0.377 \\
\hline Chronic heart failure & $7(33.3)$ & $25(20.7)$ & 0.199 \\
\hline Atrial fibrillation & $17(81)$ & $70(57.9)$ & 0.045 \\
\hline Myocardial infarction & $2(9.5)$ & $2(1.7)$ & 0.104 \\
\hline \multicolumn{4}{|l|}{ Comedication } \\
\hline $\begin{array}{l}\text { Angiotensin-converting- } \\
\text { enzyme inhibitor }\end{array}$ & $2(10.5)$ & $19(18.8)$ & 0.383 \\
\hline $\begin{array}{l}\text { Angiotensin II receptor } \\
\text { blocker }\end{array}$ & $4(21.1)$ & $19(18.8)$ & 0.820 \\
\hline Antiplatelet drugs & $0(0)$ & $4(3.8)$ & 0.398 \\
\hline Calcium channel blocker & $4(21.1)$ & $19(18.8)$ & 0.820 \\
\hline Diuretics & $9(47.4)$ & $35(34.7)$ & 0.291 \\
\hline Statins & $0(0)$ & $4(4.0)$ & 0.378 \\
\hline Valve position & & & 0.740 \\
\hline Aortic & $6(28.6)$ & $28(23.1)$ & \\
\hline Mitral & $9(42.9)$ & $66(54.5)$ & \\
\hline Double $^{\mathrm{a}}$ & $5(23.8)$ & $20(16.5)$ & \\
\hline Tricuspid $^{\mathrm{b}}$ & $1(4.8)$ & $7(5.8)$ & \\
\hline Valve type & & & 0.418 \\
\hline St. Jude Medical & 7 (38.9) & $39(34.2)$ & \\
\hline CarboMedics & $6(33.3)$ & $32(28.1)$ & \\
\hline ATS & $2(11.1)$ & $15(13.2)$ & \\
\hline MIRA & $1(5.6)$ & $9(7.9)$ & \\
\hline Duromedics & $2(11.1)$ & $6(5.3)$ & \\
\hline OnX & $0(0)$ & $4(3.5)$ & \\
\hline Others $^{c}$ & $0(0)$ & $9(7.9)$ & \\
\hline INR Mean \pm SD & $2.41 \pm 0.07$ & $2.45 \pm 0.10$ & 0.143 \\
\hline $\begin{array}{l}\text { Follow-up time (years) } \\
\text { Median (range) }\end{array}$ & $\begin{array}{l}14.3 \\
(1.4-29.7)\end{array}$ & $\begin{array}{l}14.7 \\
(1.0-27.7)\end{array}$ & 0.886 \\
\hline
\end{tabular}

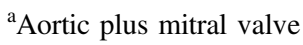

${ }^{\mathrm{b}}$ Tricuspid valve with or without other valves

${ }^{\mathrm{c}}$ Including Sorin, Bjork Shiley, D-ring, and prostheses using two or more different valve types

bleeding complications in therapeutic INR, than patients without atrial fibrillation $(p=0.045)$. 
Effects of 12 genetic variants on bleeding complications in therapeutic INR were evaluated (Table 2). All $A P O B$ SNPs were in exons, and these consisted of four nonsynonymous (c.13013G >A, c. $1853 \mathrm{C}>\mathrm{T}$, c. $1594 \mathrm{C}>\mathrm{T}$, and c. $293 \mathrm{C}>\mathrm{T}$ ) and one synonymous SNP (c.7545C $>\mathrm{T})$. Of the five $A P O E$ SNPs, two were nonsynonymous (c.388T $>\mathrm{C}$ and c. $526 \mathrm{C}>\mathrm{T}$ ). g.4798T $>\mathrm{G}$, g.6406G $>\mathrm{A}$, and g.10413T $>\mathrm{C}$ were in promoter, intron, and 3'UTR region, respectively. Observed genotype frequencies were consistent with the HWE except for two SNPs (c.1853C $>$ T and c.7545C $>$ T). Moderate degree of LD was observed between c.1853C $>\mathrm{T}$ and c.293C $>\mathrm{T}\left(\mathrm{r}^{2}=0.628\right)$. As shown in Table 2, statistically significant associations between genotypes and bleeding complications were revealed for c.1853C $>\mathrm{T}$, c. $293 \mathrm{C}>\mathrm{T}$, and c. $7545 \mathrm{C}>\mathrm{T}$ in $A P O B$. Bonferroni-corrected significance level for 12 SNPs was $0.0042(0.05 / 12)$, and after Bonferroni correction both c.1853C $>\mathrm{T}$ and c.293C $>\mathrm{T}$ remained statistically significant. For c. $1853 \mathrm{C}>\mathrm{T}, \mathrm{C}$ allele carriers experienced more bleeding complications than patients with TT genotypes (33.3\% versus $7.8 \%, p<0.001$ ). In the case of c.293C>T, 12 out of 32 patients (37.5\%) with $\mathrm{T}$ allele had bleeding complications, whereas 9 of 110 of patients $(8.2 \%)$ with CC genotype had bleeding complications $(p<0.001)$. For c.7545C $>\mathrm{T}$, patients with variant allele carriers revealed higher bleeding risk, compared to patients with wild type homozygote $(35.3 \%$ versus $12.0 \%$, $p=0.011$ ); however, it did not remain significant after Bonferroni correction. None of the APOE SNPs showed significant difference in risk of bleeding. The post hoc power calculations showed that our study (21 cases and 121 controls) had $95.3 \%$ and $96.9 \%$ statistical power for c. $1853 \mathrm{C}>\mathrm{T}(\mathrm{MAF}=0.162)$ and c. $293 \mathrm{C}>\mathrm{T}(\mathrm{MAF}=0.130)$, respectively, assuming a significance level of 0.05 .

Since there was moderate $\mathrm{LD}$ between $A P O B$ c. $1853 \mathrm{C}>\mathrm{T}$ and c.293C $>\mathrm{T}\left(\mathrm{r}^{2}=0.628\right)$, two models were constructed for multivariate analysis (Table 3). Model I included c. $1853 \mathrm{C}>\mathrm{T}$ and Model II included c.293 C $>\mathrm{T}$ in addition to age, sex, and factors having $p<0.05$ from univariate analysis. After adjusting for related covariates, carriers of $\mathrm{C}$ allele in c. $1853 \mathrm{C}>\mathrm{T}$ revealed approximately 6.4 -fold higher bleeding complications than patients with TT genotype $(p<0.001)$. In Model II, age $(\mathrm{AOR}=1.1,95 \%$ CI $1.00-1.10, p=0.035)$ and $\mathrm{T}$ allele carriers of $\mathrm{c} .293 \mathrm{C}>\mathrm{T}$ $(\mathrm{AOR}=8.6,95 \% \quad$ CI $2.9-25.5, p<0.001)$ were significantly associated with bleeding risk. In constructed models, attributable risks of $\mathrm{c} .1853 \mathrm{C}>\mathrm{T}$ and c. $293 \mathrm{C}>\mathrm{T}$ were $84.3 \%$ and $88.3 \%$, respectively. The AUROC values of Model I and Model II were 0.771 and 0.802 , respectively (Fig. 1). The Hosmer-Lemeshow test showed that the fitness of both of models were satisfactory $\left(\chi^{2}=5.415,8\right.$ degrees of freedom, $p=0.712$ for Model I; $\chi^{2}=7.146,8$ degrees of freedom, $p=0.521$ for Model II).
We calculated the number needed to genotype for preventing one patient with risk allele from experiencing higher incidence of bleeding complications using each model, obtaining 13.0 and 13.4 for $A P O B$ c. $1853 \mathrm{C}>\mathrm{T}$ and for c.293C $>\mathrm{T}$, respectively.

\section{Discussion}

Results of this study suggested that two SNPs of $A P O B$ (c.293C $>\mathrm{T}$ and c.1853C $>\mathrm{T}$ ) were associated with bleeding complications, after stabilization of warfarin response in Korean patients with mechanical heart valves. $\mathrm{T}$ allele carriers of c.293C $>\mathrm{T}$ had 8.6 times (95\% CI 2.9-25.5) increased risk of bleeding, and attributable risk was $88.3 \%$. $\mathrm{C}$ allele carriers of c.1853C $>\mathrm{T}$ had 6.4 times $(95 \% \mathrm{CI}$ 2.3-17.9) increased risk of bleeding, after adjusting for covariates (attributable risk of $84.3 \%$ ). The number needed to genotype was calculated to be around 13 in both c. $1853 \mathrm{C}>\mathrm{T}$ and c. $293 \mathrm{C}>\mathrm{T}$. AUROC values of models that included c. $1853 \mathrm{C}>\mathrm{T}$ and c. $293 \mathrm{C}>\mathrm{T}$, were 0.771 and 0.802 , respectively. Among demographic characteristics, age was the only significant risk factor, for bleeding complications after adjusting for covariates.

APOB is on the surface of LDL particles and transports cholesterol and triglycerides in the blood stream. It has been reported that lipoprotein disorders affected platelet functions, and hypersensitive platelets were observed in various stages of hyperlipidemia. Especially, LDL, a circulating complex of lipids and proteins increased in hypercholesterolemia, enhances platelet function and platelet sensitization. Hence, it was assumed that APOB levels could affect bleeding complications. A study revealed that APOB increase resulted in bleeding complications. In the study, each 1-SD elevation in APOB increased subarachnoid hemorrhage by 1.14-fold [19]. However, with respect to association between blood lipid levels and bleeding complications, results are inconsistent. Some studies revealed low lipid levels were associated with increasing risk of intracerebral hemorrhage [20-22]. In contrast, several studies reported that increased cholesterol concentrations resulted in higher bleeding rates $[23,24]$.

Both $A P O B$ c. $293 \mathrm{C}>\mathrm{T}$ and c. $1853 \mathrm{C}>\mathrm{T}$ are in domains critical for lipidation of APOB. Moreover, c.293C $>\mathrm{T}$ has been suggested to affect activation of APOB and LDL during cholesterol transport [25]. A previous study showed that $\mathrm{c} .293 \mathrm{C}>\mathrm{T}$ and $\mathrm{c} .1853 \mathrm{C}>\mathrm{T}$ were associated with $\mathrm{LDL}$ and total cholesterol levels [26]. Specifically, it was revealed that polymorphism of c.293C $>\mathrm{T}$ increased LDL concentration, whereas that of c. $1853 \mathrm{C}>\mathrm{T}$ decreased LDL concentration [27]. So, it was speculated that the higher bleeding complications in patients with mutant allele in 


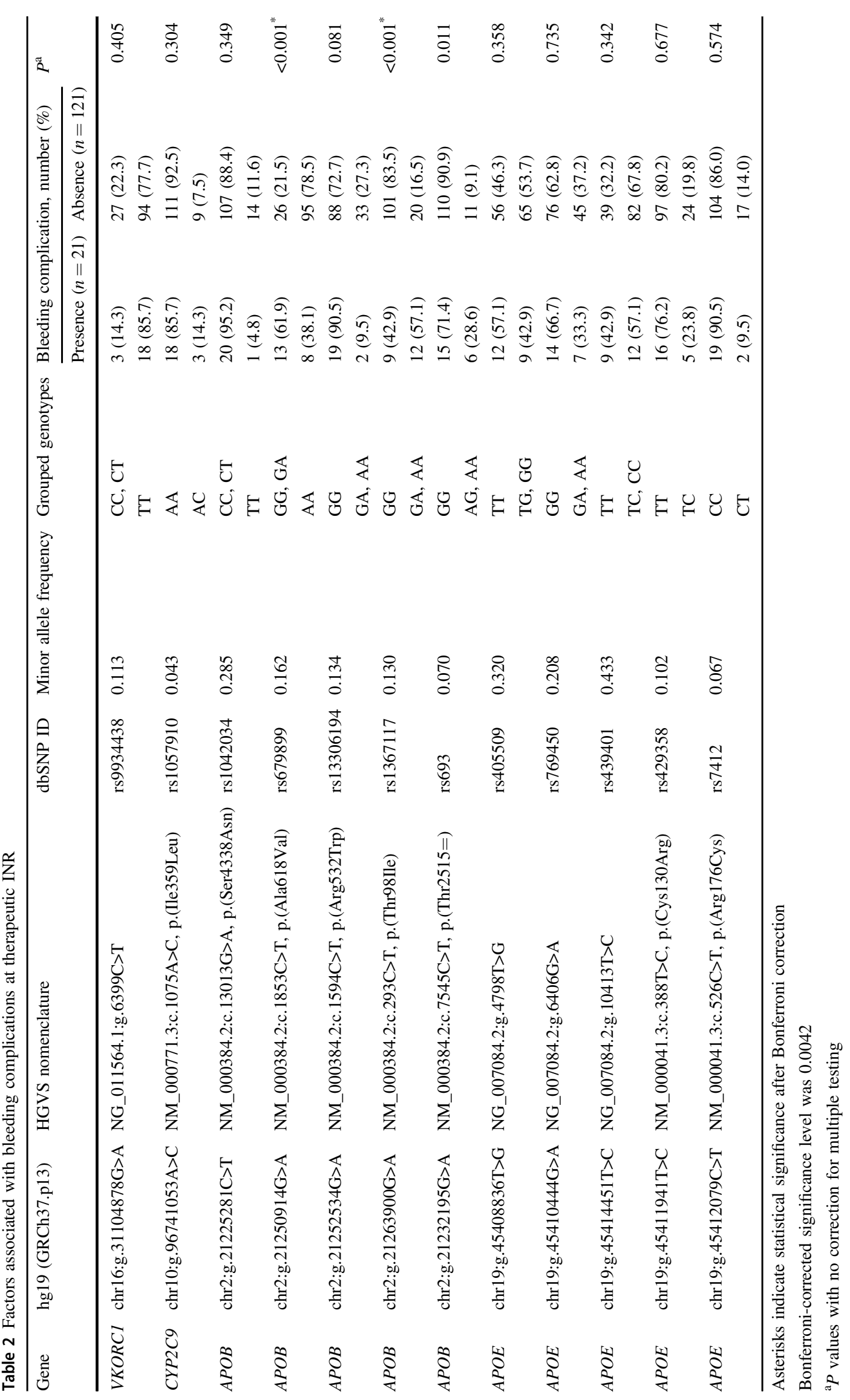


Table 3 Univariate and multivariate analyses to identify predictors for bleeding complications at therapeutic INR

\begin{tabular}{|c|c|c|c|c|c|}
\hline \multirow[t]{2}{*}{ Variables } & \multirow[t]{2}{*}{ Crude OR $(95 \% \mathrm{CI})$} & \multicolumn{2}{|l|}{ Model I } & \multicolumn{2}{|l|}{ Model II } \\
\hline & & Adjusted OR (95\% CI) & Attributable risk (\%) & Adjusted OR $(95 \% \mathrm{CI})$ & Attributable risk $(\%)$ \\
\hline Male & $1.08(0.41-2.80)$ & & & & \\
\hline Age, years & $1.03(0.99-1.08)$ & $1.05(0.99-1.10)$ & & $1.06(1.00-1.12)^{*}$ & \\
\hline $\begin{array}{l}\text { Atrial fibrillation } \\
A P O B \text { (NM_000384. }\end{array}$ & $3.10(0.98-9.75)$ & $2.93(0.88-9.84)$ & & $2.74(0.81-9.29)$ & \\
\hline $\begin{array}{l}\text { c. } 1853 \mathrm{C}>\mathrm{T}, \mathrm{C} \text { allele } \\
\text { carrier }\end{array}$ & $5.94(2.22-15.85)^{* *}$ & $6.38(2.28-17.85)^{* *}$ & 84.3 & & \\
\hline $\begin{array}{l}\text { c. } 293 \mathrm{C}>\mathrm{T}, \mathrm{T} \text { allele } \\
\text { carrier }\end{array}$ & $6.73(2.51-18.09)^{* *}$ & & & $8.55(2.87-25.46)^{* *}$ & 88.3 \\
\hline
\end{tabular}

Logistic regression analyses were carried out with variables of sex, age, atrial fibrillation, and c.1853C $>\mathrm{T}$ for Model $\mathrm{I}$, and sex, age, atrial fibrillation, and c.293C $>$ T for Model II

$* p<0.05, * * p<0.001$

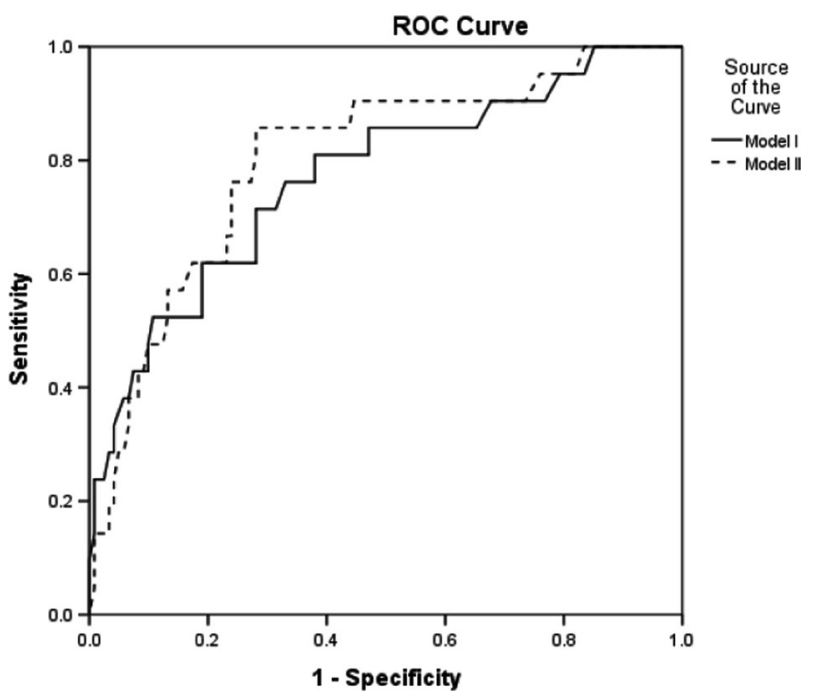

Fig. 1 Area under receiver operating characteristic curve for bleeding complications at therapeutic INR. AUC for Model I is $0.771(95 \%$ CI $0.654-0.887, p<0.001)$, and AUC for Model II is 0.802 (95\% CI $0.699-0.905, p<0.001)$

c. $293 \mathrm{C}>\mathrm{T}$, and wild allele in c. $1853 \mathrm{C}>\mathrm{T}$, were possibly attributed to increased concentrations in LDL and cholesterol.

$A P O B$ c. $7545 \mathrm{C}>\mathrm{T}$ is a synonymous SNP. A study on Chinese population reported that $\mathrm{c} .7545 \mathrm{C}>\mathrm{T}$ polymorphism was associated with cerebral hemorrhage. However, this SNP failed to reveal significance after Bonferroni correction in our study. Since the Chinese study did not conduct a correction on multiple testing, it was difficult to compare their results with ours [28].

APOE is known to be a strong risk factor for warfarinrelated hemorrhage [29, 30]. Especially, APOE c.526C $>\mathrm{T}$ and c.388T $>C$ increased risk of warfarin-related bleeding complications [31, 32]. However, Asian populations including Koreans have very low frequency of $A P O E \varepsilon$ variants. In addition, variant-type homozygotes in $A P O E$ c.526C $>\mathrm{T}$ and c.388T $>\mathrm{C}$ are very rare; there were no patients with variant-type homozygote of c.526C $>\mathrm{T}$ and c.388T $>C$ in our study population. The reason for lack of statistical significance in APOE SNPs with bleeding in this study was probably due to low frequency of variants.

VKORC1 and CYP2C9 have significant effects on warfarin response [33]. Our study did not reveal correlation between these two genes and bleeding risks. Since patients with polymorphisms of VKORC1 or CYP2C9 had dose adjustment according to INR measurement, increased risk of bleeding complication was not expected in our study.

Age plays an important role in bleeding complication, related to warfarin treatment. A previous cohort study including patients on warfarin showed that risk of major hemorrhage increases with older age [34]. Our study also revealed that older age was significantly associated with increased bleeding risk.

To evaluate the potential clinical value of genotyping SNPs which were found to be significant in this study, we calculated the number needed to genotype for preventing one $\mathrm{C}$ allele carrier in $A P O B$ c. $1853 \mathrm{C}>\mathrm{T}$ and one $\mathrm{T}$ allele carrier in $A P O B$ c. $293 \mathrm{C}>\mathrm{T}$ from experiencing higher incidence of bleeding complications. Using the equations, 13 and 13.4 were obtained in c.1853C $>\mathrm{T}$ and c.293C $>\mathrm{T}$, respectively, indicating that prospective genotyping of the SNPs could be cost-effective in clinical practice. Therefore, it would be advisable to detect $\mathrm{C}$ allele carriers in c. $1853 \mathrm{C}>\mathrm{T}$ and $\mathrm{T}$ allele carriers in c.293C $>\mathrm{T}$ before warfarin initiation, which would then allow methods to prevent bleedings.

The limitations of our study are a single ceter study with a small sample size and retrospective design. Another limitation is that we were unable to obtain lipid or APOB levels. Therefore, it is difficult to demonstrate underlying 
mechanisms of bleeding complications. Also, since this study dealt with patients with INR $2-3$, only minimal or minor bleeding events were observed. While there is no doubt that fatal and major hemorrhages are of essential importance, minor bleedings are also important, because they serve as an alert for subsequent major bleedings and may increase the number of visits to clinics and sometimes the emergency room, which results in additional expenditures. However, given the only minor and minimal bleeding complications, it is uncertain if these SNPs may play important roles in major bleeding complications. Therefore, further studies using a larger sample size and multicenter design are needed.

Despite shortcomings, this study provides compelling evidence for prediction of bleeding risks regarding warfarin usage. Our study is the first to develop prediction models using $A P O$ gene polymorphisms, for bleeding risk factors in patients taking warfarin. In addition, we performed Bonferroni correction, although it is not necessary since Bonferroni correction is considered overly conservative for a hypothesisgenerating study and this study is intended to find candidate genes for the bleeding complications. Results of this study could be used to develop and implement individually tailored intervention strategies, such as posttherapeutic dose adjustment, to prevent warfarin-induced bleeding risks.

Acknowledgements This study was supported by Basic Science Research Program through the National Research Foundation of Korea (NRF) funded by the Ministry of Education (no. 2017R1D1A1B03034033).

\section{Compliance with ethical standards}

Conflict of interest The authors declare that they have no conflict of interest.

Publisher's note: Springer Nature remains neutral with regard to jurisdictional claims in published maps and institutional affiliations.

\section{References}

1. Nishimura R, Otto C, Bonow R, Carabello BA, Erwin JP 3rd, Guyton RA, et al. 2014 AHA/ACC guideline for the management of patients with valvular heart disease: executive summary: a report of the American college of Cardiology/American heart association task force on practice guidelines. Circulation. 2014;129:2440-92.

2. Puri D, Kumar A, Basu R, Chaudhary A, Sarwal V, Sahoo M, et al. Early anticoagulation after mechanical valve implantation, and related complications. J Heart Valve Dis. 2008;17:418-24.

3. Grzymala-Lubanski B, Svensson P, Renlund H, Jeppsson A, Själander A. Warfarin treatment quality and prognosis in patients with mechanical heart valve prosthesis. Heart. 2017;103:198-203.

4. Cannegieter S, Rosendaal F, Briët E. Thromboembolic and bleeding complications in patients with mechanical heart valve prostheses. Circulation. 1994;89:635.
5. Keeling D, Baglin T, Tait C, Watson H, Perry D, Baglin C, et al. Guidelines on oral anticoagulation with warfarin-fourth edition. Br J Haematol. 2011;154:311-24.

6. Johnson JA, Caudle KE, Gong L, Whirl-Carrillo M, Stein CM, Scott SA, et al. Clinical pharmacogenetics implementation consortium (CPIC) guideline for pharmacogenetics-guided warfarin dosing: 2017 update. Clin Pharmacol Ther. 2017;102:397-404.

7. Ferder NS, Eby CS, Deych E, Harris JK, Ridker PM, Milligan PE, et al. Ability of VKORC1 and CYP2C9 to predict therapeutic warfarin dose during the initial weeks of therapy. J Thromb Haemost. 2010;8:95-100.

8. Palareti G, Leali N, Coccheri S, Poggi M, Manotti C, D’Angelo A, et al. Bleeding complications of oral anticoagulant treatment: an inception-cohort, prospective collaborative study (ISCOAT). Italian study on complications of oral anticoagulant therapy. Lancet. 1996;348:423-8.

9. Abdelhafiz AH, Wheeldon NM. Risk factors for bleeding during anticoagulation of atrial fibrillation in older and younger patients in clinical practice. Am J Geriatr Pharmacother. 2008;6:1-11.

10. Shoeb M, Fang MC. Assessing bleeding risk in patients taking anticoagulants. J Thromb Thrombolysis. 2013;35:312-9.

11. Yang J, Chen Y, Li X, Wei X, Chen X, Zhang L, et al. Influence of CYP2C9 and VKORC1 genotypes on the risk of hemorrhagic complications in warfarin-treated patients: a systematic review and meta-analysis. Int J Cardiol. 2013;168:4234-43.

12. Korporaal S, Relou I, van Eck M, Strasser V, Bezemer M, Gorter $\mathrm{G}$, et al. Binding of low-density lipoprotein to platelet apolipoprotein $\mathrm{E}$ receptor 2 results in phosphorylation of p38MAPK. J Biol Chem. 2004;279:52526-34.

13. Riddell D, Owen J. Inhibition of ADP-induced platelet aggregation by APOE is not mediated by membrane cholesterol depletion. Thromb Res. 1996;81:597-606.

14. Mehran R, Rao SV, Bhatt DL, Gibson CM, Caixeta A, Eikelboom $\mathrm{J}$, et al. Standardized bleeding definitions for cardiovascular clinical trials: a consensus report from the Bleeding Academic Research Consortium. Circulation. 2011;123:2736-47.

15. Barrett J, Fry B, Maller J, Daly M. Haploview: analysis and visualization of LD and haplotype maps. Bioinformatics. 2005;21:263-5.

16. Ward L, Kellis M. HaploRegv4: systematic mining of putative causal variants, cell types, regulators and target genes for human complex traits and disease. Nucleic Acids Res. 2016;44:D877-81.

17. Hu Z, Zhang L, Yang Q. Effect of APOB polymorphism on plasma lipid levels and cerebral hemorrhage in Changsha Han Chinese. Zhong Nan Da Xue Xue Bao Yi Xue Ban. 2008;33:494-9.

18. Utermann G. Apolipoprotein E polymorphism in health and disease. Am Heart J. 1987;113:433-40.

19. Lindbohm J, Korja M, Jousilahti P, Salomaa V, Kaprio J. Adverse lipid profile elevates risk for subarachnoid hemorrhage: a prospective population-based cohort study. Atherosclerosis. 2018;274:112-9.

20. Valappil A, Chaudhary N, Praveenkumar R, Gopalakrishnan B, Girija A. Low cholesterol as a risk factor for primary intracerebral hemorrhage: a case-control study. Ann Indian Acad Neurol. 2012;15:19-22.

21. Tanaka H, Ueda Y, Hayashi M, Date C, Baba T, Yamashita H, et al. Risk factors for cerebral hemorrhage and cerebral infarction in a Japanese rural community. Stroke. 1982;13:62-73.

22. Shimamoto T, Komachi $Y$, Inada H, Doi M, Iso H, Sato S, et al. Trends for coronary heart disease and stroke and their risk factors in Japan. Circulation. 1989;79:503-15.

23. Korja M, Silventoinen K, Laatikainen T, Jousilahti P, Salomaa V, Hernesniemi J, et al. Risk factors and their combined effects on the incidence rate of subarachnoid hemorrhage - a populationbased cohort study. PLoS ONE. 2013;8:e73760. 
24. Zhang Y, Tuomilehto J, Jousilahti P, Wang Y, Antikainen R, Hu G. Total and high-density lipoprotein cholesterol and stroke risk. Stroke. 2012;43:1768-74.

25. Chatterton J, Schlapfer P, Butler E, Gutierrez MM, Puppione DL, Pullinger CR, et al. Identification of apolipoprotein B100 polymorphisms that affect low-density lipoprotein metabolism: description of a new approach involving monoclonal antibodies and dynamic light scattering. Biochemistry. 1995;34:9571-80.

26. Zhou Y, Mägi R, Milani L, Lauschke V. Global genetic diversity of human apolipoproteins and effects on cardiovascular disease risk. J Lipid Res. 2018;59:1987-2000.

27. Benn M, Stene M, Nordestgaard B, Jensen GB, Steffensen R, Tybjaerg-Hansen A. Common and rare alleles in apolipoprotein B contribute to plasma levels of low-density lipoprotein cholesterol in the general population. J Clin Endocrinol Metab. 2008;93:1038-45.

28. Zhang L, Yang QD, Zeng Y. Positive association of apolipoprotein $\mathrm{B}$ gene $\mathrm{C} 7673 \mathrm{~T}$ polymorphism with cerebral hemorrhage with family history. Zhonghua Yi Xue Yi Chuan Xue Za Zhi. 2008;25:145-9.
29. Falcone G, Radmanesh F, Brouwers H, Battey TW, Devan WJ, Valant V, et al. APOE $\varepsilon$ variants increase risk of warfarin-related intracerebral hemorrhage. Neurology. 2014;83:1139-46.

30. He S, Zhang H, Cao Y, Nian F, Chen H, Chen W, et al. Association between apolipoprotein $\mathrm{E}$ genotype and warfarin response during initial anticoagulation. Biomed Pharmacother. 2018;101:251-6.

31. Ma Y, Li Z, Chen L, Li X. Blood lipid levels, statin therapy and the risk of intracerebral hemorrhage. Lipids Health Dis. 2016;15:43.

32. Kim B, Lee S, Ryu W, Kang BS, Kim CK, Yoon BW. Low level of low-density lipoprotein cholesterol increases hemorrhagic transformation in large artery atherothrombosis but not in cardioembolism. Stroke. 2009;40:1627-32.

33. Lee Y, Eggen J, Soni V, Drozda K, Nutescu EA, Cavallari LH. Warfarin dose requirements in a patient with the CYP2C9*14 allele. Pharmacogenomics. 2014;15:909-14.

34. Fang M, Go A, Hylek E, Chang Y, Henault LE, Jensvold NG, et al. Age and the risk of warfarin-associated hemorrhage: the anticoagulation and risk factors in atrial fibrillation study. J Am Geriatr Soc. 2006;54:1231-6. 